\title{
Effect of Italian Sour Cherry (Prunus cerasus L.) on the Formation of Advanced Glycation End Products and Lipid Peroxidation
}

\author{
Gianna Ferretti ${ }^{1}$, Davide Neri ${ }^{2}$, Tiziana Bacchetti ${ }^{3 *}$ \\ ${ }^{1}$ Dipartimento d Scienze Cliniche Sperimentali e Odontostomatologiche, Università Politecnica delle Marche, \\ Ancona, Italy \\ ${ }^{2}$ SAPROV-Dipartimento di Scienze Ambientali e delle Produzioni Vegetali, Università Politecnica delle Marche, \\ Ancona, Italy \\ ${ }^{3}$ Dipartimento di Scienze della Vita e dell'Ambiente, Università Politecnica delle Marche, \\ Ancona, Italy \\ Email: g.ferretti@univpm.it, d.neri@univpm.it, ${ }^{*}$ t.bacchetti@univpm.it
}

Received 19 June 2014; revised 25 July 2014; accepted 8 August 2014

Copyright (C) 2014 by authors and Scientific Research Publishing Inc.

This work is licensed under the Creative Commons Attribution International License (CC BY). http://creativecommons.org/licenses/by/4.0/

\section{c) (i) Open Access}

\section{Abstract}

Sweet and sour cherries contain several polyphenols that possess antioxidant and anti-inflammatory properties. Aim of this study was to investigate the effect of the maturity stage on phenol content and biological properties of extract of a local Morello-type of sour cherry (Prunus cerasus L.), "visciola". The study of total phenol content and total antioxidant potential was associated with the evaluation of the antioxidant property of extracts using a copper catalyzed human low density lipoproteins (LDL) oxidation as experimental model. Moreover, using albumin glycated by methylglyoxal, we evaluated the anti-glycation effect of fruit extract. The results demonstrated that fully ripened fruits exert higher antioxidant and anti-glycation properties when compared with partially ripened fruits. Information about the health-promoting components of "visciola" could lead to a better understanding and an increased consumption of these, including its use as functional food.

\section{Keywords}

Sour Cherry, "Visciola", Antioxidants, Fruit Maturation, LDL Oxidation, Glycation, Methylglyoxal, Advanced Glycation End Products, Polyphenols

\footnotetext{
${ }^{*}$ Corresponding author.
}

How to cite this paper: Ferretti, G., Neri, D. and Bacchetti, T. (2014) Effect of Italian Sour Cherry (Prunus cerasus L.) on the Formation of Advanced Glycation End Products and Lipid Peroxidation. Food and Nutrition Sciences, 5, 1568-1576. 


\section{Introduction}

Previous studies have demonstrated that several fruit phytochemicals exert antioxidant and anti-inflammatory properties [1] [2]. Beyond antioxidant properties, some phytochemicals display hypoglycaemic activities [3] [4]. Recent studies have also shown that some fruit phenolics inhibit the formation of advanced glycation end products (AGEs) [5]-[10], whose formation and accumulation exert a pathophysiological role in patients with diabetes, renal and neurodegenerative disease as well as some types of cancer [11] [12]. AGEs, produced through non-enzymatic reactions between reducing sugars and proteins, nucleic acids or lipids, induce oxidative stress and molecular cross linkages that cause cellular and tissue damage by impairing protein function and clearance [13] [14]. The biological activities exerted by fruit phytochemicals are believed to contribute to the overall health-protective effect of fruits and vegetables because they may mitigate the consequences of oxidative stress in disease development and aging process [15] [16].

Among fruits, sweet and sour cherry (Prunus spp.) phytochemicals have been previously characterized. The phenolic composition in sour and sweet cherries includes flavonoids such as anthocyanins, flavan-3-ols, flavonols and phenolics acids whose biological properties have been demonstrated in different experimental models and reviewed [17] [19]. Antioxidant properties of cherry phytonutrients have been reported both in vitro [17][22] and in vivo studies [23]-[25]. Several studies have demonstrated that the synthesis of antioxidant phytochemicals is modulated by genetic and environmental factors such as fruit variety, maturity stage and processing [17] [26] [27]. Studies of ripening are of special interest because they allow the identification of the optimum point of maturity for harvesting and enable delivery of fruit to consumers in its best condition in terms of nutritional and functional properties. Little is known about the effect of ripening on phytonutrients contained in the local variety of sour cherry (Prunus cerasus L.) morellos, var. austere L., known in Marche region, Italy, as "visciola".

Aim of this study was to investigate the effect of the maturity stage on phenol content and nutraceutical properties of this variety of sour cherry. Therefore, we evaluated the anti-glycation and antioxidant properties of fruit extracts using methylglyoxal-glycated albumin and copper catalyzed oxidation of human low density lipoproteins (LDL), as experimental models.

\section{Materials and Methods}

\subsection{Chemicals}

All reagents, including fluorescein, 6-hydroxy-2,5,7,8-tetramethylchroman-2-carboxylic acid (Trolox), 2,20azobis(2-methylpropionamidine)dihydrochloride (AAPH), copper-sulfate, methylglyoxal (MGO), serum bovine albumin (BSA), Folin-Ciocalteau reagent, gallic acid, 2,2-diphenyl-1-picrylhydrazyl (DPPH) and solvents were purchased from Sigma-Aldrich Chemical Co (Milan, Italy).

\subsection{Fruit Soluble Solids, Titratable Acidity}

Sour cherries (Prunus cerasus L.) local Morellos type "visciola" of two native different clones (A and B) were from an experimental farm in Castelbellino (AN, Italy) and were harvested in 2009 at two different stages of ripeness: partially ripen (PR) and fully ripen (FN). Acidity was titrated using $10 \% \mathrm{NaOH}$ water solution and expressed as tartaric acid $(\mathrm{g} / \mathrm{L})$ while soluble solid content of the juice ( ${ }^{\circ}$ brix) was determined using a hand refractometer (Hand refractometer, Atago LTD, Tokyo, JP).

"Visciola" samples (at least 30 fruits) were pitted, packed and stored at $-20^{\circ} \mathrm{C}$ until analyzed.

\subsection{Determination of Total Phenol Content}

"Visciola" (approximately $20 \mathrm{mg}$ ) were homogenized using an Ultra-Turrax T25 for $5 \mathrm{~min}$ at $30 \mathrm{~Hz}$ in $2 \mathrm{~mL}$ ice-cold 50\% acetone. To avoid degradation of pigments and phenolic compounds, the homogenization was carried out in ice and darkness. Samples were centrifuged ( $4500 \mathrm{~g}$ for $30 \mathrm{~min}$ at $4^{\circ} \mathrm{C}$ ) and filtered through Whatman n. 4 filter paper.

Total phenol content of the extracts was determined using the Folin-Ciocalteu reagent [28]. Briefly, appropriately diluted extracts $(0.050 \mathrm{~mL})$ and $1.5 \mathrm{~mL}$ of water were added followed by $0.125 \mathrm{~mL}$ of Folin-Ciocalteau reagent and mixed. After $1 \mathrm{~min}, 0.375 \mathrm{~mL}$ of $20 \% \mathrm{Na}_{2} \mathrm{CO}_{3}$ and $0.450 \mathrm{~mL}$ of water were added to reach a final 
volume of $2.5 \mathrm{~mL}$. After mixing, samples were left for $2 \mathrm{hrs}$ at room temperature in the dark. The absorbance was then read at $760 \mathrm{~nm}$ against blank. The results were expressed as mg gallic acid equivalents (GAE) in $100 \mathrm{~g}$ of fruit [28].

\subsection{Determination of Total Antioxidant Capacity}

Total antioxidant capacity of the fruit extracts was evaluated using oxygen radical absorbance capacity method (ORAC) and by scavenging of the radical 2,2-diphenyl-1-picrylhydrazyl (DPPH).

ORAC assay was carried out on a plate reader [29]. Briefly, AAPH was used as peroxyl radical generator, trolox as standard, and fluorescein as fluorescent probe. Fluorescence filters were used for an excitation wavelength of $485 \mathrm{~nm}$ and an emission wavelength of $530 \mathrm{~nm}$. $20 \mu \mathrm{L}$ of diluted sample, blank, or trolox calibration solutions were mixed with $150 \mu \mathrm{L}$ of $0.08 \mu \mathrm{M}$ fluorescein and incubated for $15 \mathrm{~min}$ at $37^{\circ} \mathrm{C}$ before injection of $25 \mu \mathrm{L}$ of AAPH solution $(150 \mathrm{mM})$. The fluorescence was measured every $2 \mathrm{~min}$ for $4 \mathrm{~h}$. All samples were analyzed in triplicate. The final ORAC values were calculated using the net area under the decay curves and were expressed as millimoles of Trolox equivalents (TE)/100g of fruit.

Radical scavenging activity of samples was evaluated by monitoring the decrease of absorbance at $517 \mathrm{~nm}$ of methanolic solution of the radical 2,2-diphenyl-1-picrylhydrazyl (DPPH) (stock solution $200 \mathrm{mM}$ ) incubated for 5 minutes in the absence $(\mathrm{Ab})$ or in the presence (Ac) of samples. Radical scavenging activity was calculated by the following formula: \% inhibition $=[(\mathrm{Ab}-\mathrm{Ac}) / \mathrm{Ab}] \times 100$. Results were expressed as micromoles of Trolox equivalents (TE)/100g of fruit [30].

\subsection{LDL Isolation and Oxidation}

LDL particles were isolated from pooled fresh human blood obtained from volunteers after overnight fasting. Blood was collected in heparin-containing vacutainers and plasma was obtained by centrifugation at $3000 \mathrm{rpm}$ for 15 minutes. LDL (density between 1.025 and $1.063 \mathrm{~g} / \mathrm{ml}$ ) were isolated by single vertical spin gradient ultracentrifugation on a Sorvall RC-150GX ultracentrifuge following the procedure described by Chung et al. [31]. After dialysis at $4^{\circ} \mathrm{C}$ for $24 \mathrm{~h}$ against $5 \mathrm{mM}$ PBS pH 7.4, protein concentration was determined by the method of Bradford [32]. Antioxidant activities were assessed by direct monitoring of the retardation of conjugated diene formation at $234 \mathrm{~nm}$ during copper-induced oxidation of human LDL [33]. Conjugated dienes were evaluated in LDL incubated in the presence and absence of fruit extracts in a 96-well microplate reader. Briefly $0.01 \mathrm{~mL}$ of extract were added to $0.02 \mathrm{~mL}$ of LDL ( $1 \mathrm{mg}$ protein/mL). The volume of each well was adjusted with deionized water to reach the final volume of $0.2 \mathrm{~mL}$. The oxidation reaction was initiated by adding $0.01 \mathrm{ml}$ of $0.1 \mathrm{mM}$ $\mathrm{Cu}^{2+}$ (final concentration $5 \mu \mathrm{M}$ ) to each well and conjugated dienes were monitored at $234 \mathrm{~nm}$ for $4 \mathrm{~h}$ at $37^{\circ} \mathrm{C}$.

\subsection{In Vitro Glycation of BSA}

The non-enzymatic glycation of BSA was induced in vitro using methylglyoxal (MGO). Briefly BSA (1 mg/mL) was incubated with MGO to a final concentration of $5 \mathrm{mM}$ for 72 hours at $37^{\circ} \mathrm{C}$ in presence of sodium azide $(0.02 \%)$ [34]. The incubation was carried out in the absence (MGO-BSA) or in the presence of fruit extract (MGO-BSA-SAMPLE). Different concentrations of the extracts were used $(0.1-10 \mathrm{mg} / \mathrm{mL}$ ).

The reaction of non-enzymatic glycation of samples was investigated by evaluating the increase in intrinsic fluorescence associated to the formation of advanced glycation fluorescent products. Samples were analyzed with an excitation/emission wavelength pair $365 \mathrm{~nm} / 440 \mathrm{~nm}$.

Results were reported as percent inhibition of MGO-induced glycation of BSA where percent inhibition = [Intensity (MGO-BSA-SAMPLE) - Intensity (BSA-SAMPLE)]/[(Intensity (MGO-BSA) - Intensity (BSA)] × 100 .

The amount of sample (mg) required to inhibit the reaction rate by $50 \%$, I50 was interpolated.

\subsection{Tryptophan Fluorescence}

Tryptophan emission florescence spectra of BSA incubated in different experimental conditions was evaluated using $295 \mathrm{~nm}$ as excitation wavelength [35].

\subsection{Statistical Analysis}

Mean value and standard deviation (SD) were calculated. ANOVA analysis and Duncan's multiple range test for 
mean separation were performed and a $\mathrm{p}<0.05$ was considered statistically significant.

\section{Results}

The fresh weight of the fruit pulp was very similar in the two "visciola" selections (clone A and clone B) with a slight increase, but not significant, in the final stage of fruit ripening. The average fresh weight for "visciola" was around $2 \mathrm{~g}$. Soluble solids content significantly increased with maturity, while the titratable acidity was not significantly modified (Figure 1(a) and Figure 1(b)).

No significant differences were observed in the total content of phenol compounds among the two selections of "visciola" (clone A and clone B) (data not shown). As summarized in Table 1, the total phenol content was significantly higher in FR fruits $(\mathrm{p}<0.001)$. Table 1 summarizes total antioxidant capacity evaluated by ORAC assay and DPPH assay. ORAC values were higher in fruits ripened at a more advanced maturity stage (FR compared with PR) $(\mathrm{p}<0.001)$. These results were confirmed using the DPPH assay $(\mathrm{p}<0.001)$. A significant correlation was observed between the ORAC values and DPPH scavenging activity $(r=0.95, p<0.001)$.

\subsection{Effect of Sour Cherry Extracts on MGO-Induced Glycation of BSA}

As shown in Figure 2, a concentration-dependent inhibitory effect on AGEs formation (from $0.1 \mathrm{mg} / \mathrm{mL}$ to 10 $\mathrm{mg} / \mathrm{mL}$ ) was exerted by "visciola" extracts. At higher concentration the inhibitory effect exerted by FR fruit reached $80 \%$. The inhibitory activity was lower in PR "visciola "than in FR fruits (IC50 = $8.8 \pm 0.3 \mathrm{mg} / \mathrm{mL}$ in PR fruits and $5.8 \pm 0.2 \mathrm{mg} / \mathrm{mL}$ in FR fruits, $\mathrm{p}<0.001$ ).

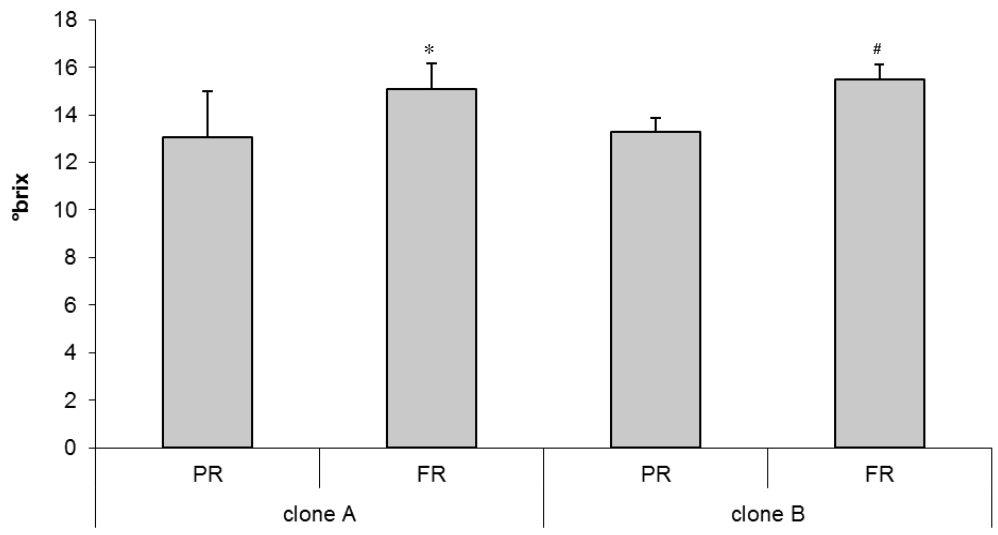

(a)

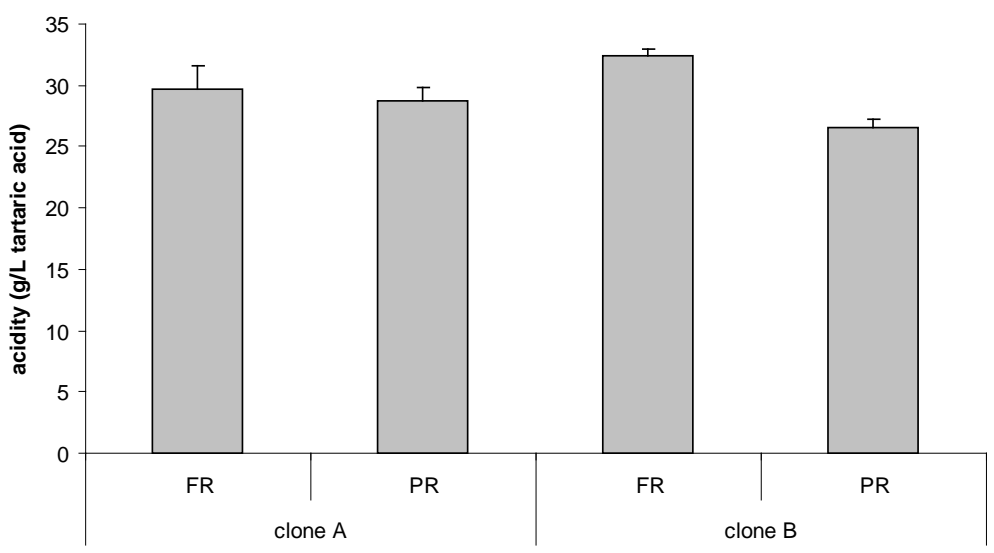

(b)

Figure 1. (a) Soluble solids content ( ${ }^{\circ}$ brix) and (b) acidity expressed as tartaric acid (g/L) in "visciola" (clone A and clone B) at different maturity stage (PR, partially ripen and FR, fully ripen). ( ${ }^{*} \mathrm{p}<0.05$ vs FR clone A; \#p $<0.05$ vs FR clone $\mathrm{B}$ ). 
Table 1. Total phenol content and total antioxidant capacity evaluated by ORAC assay and DPPH assay in "visciola” at two different maturity stage (partially ripen and fully ripen) in fresh and dried fruits.

\begin{tabular}{ccc}
\hline & Partially ripened fruit & Fully ripened fruits \\
\hline Total phenol content (mgGAE/100g FW) & $217 \pm 50$ & $311 \pm 44^{*}$ \\
ORAC (mmolTE/100g FW) & $1.96 \pm 0.25$ & $2.54 \pm 0.22^{*}$ \\
DPPH $(\mu$ mol TE/100g FW) & $115 \pm 21$ & $157 \pm 18^{*}$ \\
\hline
\end{tabular}

${ }^{*} \mathrm{p}<0.05$ vs fruit partially ripened.

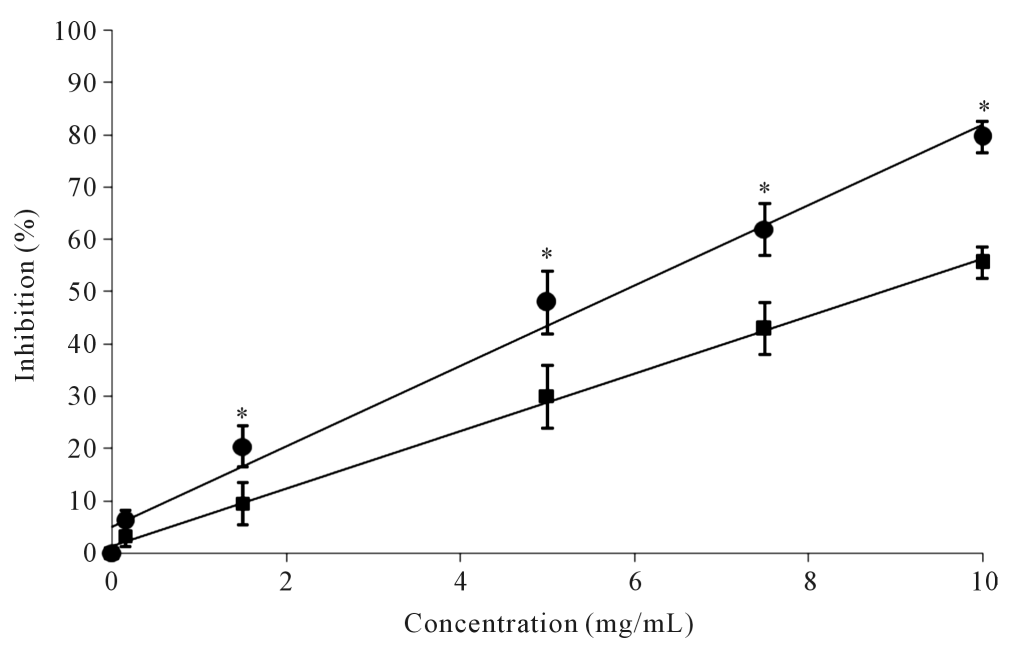

Figure 2. Protective effect of "visciola" extracts against non-enzymatic glycation of BSA induced by methylglyoxal (MGO-BSA). Dose-response curves for AGEs formation in MGO-BSA incubated in the presence of fruit extracts at different maturity stage: fully ripen, FR ( $\bullet-)$ or partially ripen, PR $(\rightarrow-) .{ }^{*} \mathrm{p}<0.05$ vs FR fruit.

Tryptophan fluorescence intensity of BSA (875 \pm 45 A.U.) was quenched by more than $70 \%$ after glycation with methylglyoxal (MGO-BSA) $(232 \pm 54$ A.U.) (p < 0.001). No significant modification was shown in BSA glycated in the presence of fruit extract at all the concentrations employed with respect to MGO-BSA (data not shown).

\subsection{Effect of Sour Cherry Extracts on LDL Oxidation}

Lag-time of conjugated diene formation during $\mathrm{Cu}^{2+}$-oxidation of LDL is a widely used index to investigate the kinetic of oxidation of LDL and to evaluate the antioxidant capacity of fruit extracts [21] [36]. Lag time in $\mathrm{Cu}^{2+}$ oxidized LDL was $69 \pm 12$ minutes (Figure 3). In LDL oxidized in the presence of fruit extracts lag time was longer suggesting a protective effect against $\mathrm{Cu}^{2+}$-triggered lipid peroxidation of LDL. Extract of PR fruit exerted a lower protective effect compared with FR fruits (Figure 3).

\section{Discussion}

Previous studies have shown that the content of nutrients in fruits is affected by the degree of maturity at harvest, genetic differences (cultivar) and processing, however, their concentration varies from plant to plant or even in different organs of the same plant at different ripening stages [17] [26] [27].

We studied phenol content and nutraceutical properties of the local germoplasm of sour cherry "visciola" from Marche (Italy). During the maturation the soluble solids in "visciola" increased without any decrease of titratable acidity. Higher levels of phenols have been measured in fully ripened "visciola" with respect to partially ripened "visciola". These data demonstrate that ripeness stage has a high influence on phenol levels of "visciola", in good agreement with data obtained in other fruits [19] [37] [38]. In fact maturation of fruit or other plant tissues 


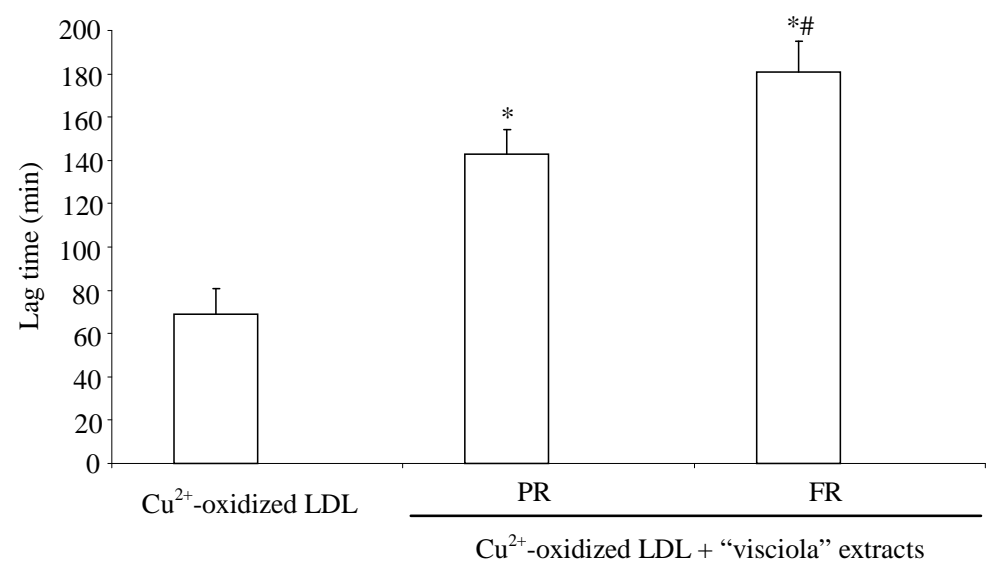

Figure 3. Protective effect of "visciola" extracts against lipid peroxidation of LDL induced by copper ions. LDL oxidized in the absence $\left(\mathrm{Cu}^{2+}\right.$-oxidized LDL) or in the presence of fruit extracts at different maturity stage: PR, partially ripen and FR, fully ripen. $\left({ }^{*} \mathrm{p}<0.05 \mathrm{vs} \mathrm{Cu}^{2+}\right.$-oxidized LDL; \#p $<$ $0.05 \mathrm{vs} \mathrm{Cu}^{2+}$-oxidized LDL incubated in the presence of PR fruit).

involves a series of complex reactions, which leads to changes in the phytochemistry of the plants. In particular, Serrano et al. have demonstrated that the enhancement in total phenolics observed in different sweet cherry cultivars at higher maturity stages was positively correlated with the increase in total anthocyanins [38].

Also the values of antioxidant potential (ORAC assay and DPPH assay) were higher in fully ripened fruits compared with partially ripened fruits. In fully ripened fresh fruits ORAC value was about 2.5 mmol Trolox equivalents (TE)/100g, in agreement with previous studies in different sour cherries such as Amarena Mattarello, Visciola Ninno, Visciola Sannicandro, Montmorency and Balaton cherries [20] [22] [39].

To further investigate the effect of maturity stage on biological properties of "visciola", we studied the effect of fruit extracts against the formation of advanced glycation end products in BSA glycated in vitro by MGO and against lipid peroxidation of human LDL induced in vitro by copper ions.

We demonstrated that "visciola" extracts exerted a protective effect against MGO-glycation of BSA. The effect realized at a higher extent in extracts obtained from fully ripened fruits. Glycation is a major source of reactive oxygen species (ROS) and reactive carbonyl species (RCS) that are generated by oxidative (glycoxidative) and non-oxidative pathways [14] [40]. Reactive dicarbonyl species, such as MGO, have received extensive attention because these compounds are highly reactive and can form AGEs with proteins, phospholipids and DNA. Structural and functional alterations have been observed in MGO-glycated protein [13] [41] [42]. Advanced glycation end-products are well-known contributors to the pathophysiology of aging and diabetic chronic complications [11] [12] [43]. Therefore, natural products containing molecules able to inhibit AGEs formation are obtaining an increasing attention. Inhibitors of glycation can act in multiple steps [10].

Previous studies have demonstrated that tryptophan fluorescence can be quenched by changes in the protein structure induced by MGO [35]. In agreement with other authors, we have shown that incubation of BSA with MGO produces dramatic changes in tryptophan fluorescence [35]. Fruit extracts displayed any significant effect on these changes which rules out any significant participation as inhibitors in the first phase of the glycation cascade. Therefore, we suggest that the inhibitory effect is due mainly to an inhibition of the second phase of the glycation reactions, namely the free-radical mediated conversion of the Amadori products to AGEs. These data suggest that fruit extracts exert these effects mainly through their antioxidant and free radical quenching capacity as reported by other authors [35]. Moreover, we observed "visciola" extracts are able to inhibit $\mathrm{Cu}^{2+}$-induced lipid peroxidation of LDL. In our experimental conditions both anti-glycation effect and antioxidant property were higher in extracts obtained by fully ripened fruits.

Fruit phytochemicals able to exert antioxidant effects have been previously studied. Not all phenol compounds in sour cherries are equally effective as antioxidants [20] [21] [36]. In LDL oxidized by copper ions, Heinonen et al. have shown that berry extracts inhibited hexanal formation in the order: blackberries $>$ red raspberries $>$ sweet cherries $>$ blueberries $>$ strawberries and that the antioxidant activity was associated directly with anthocyanins and indirectly with flavonols [21]. Using the same experimental model, Goncalves et al. [36] 
reported that antioxidant effects of the cherry samples were positively correlated with their levels of p-coumaroylquinic acid but negatively correlated with their cyanidin-3-rutinoside levels [36].

The anti-glycation activity exerted by polyphenols has been investigated and a relationship structure-inhibitory activity of flavonoids has been demonstrated [7]. In particular phenolics acids and proanthocyanidins exert also anti-glycation effects triggered by MGO [34] [44]. A MGO-trapping effect of flavonoids has been also recently demonstrated [9].

As far as concerns the physiological relevance of our results, previous studies have shown that cherry polyphenols are bioavailable [45] and their plasma concentrations range from 0.5 to $1.6 \mu \mathrm{M}$ [46]. Moreover, previous studies have demonstrated that cherries exert antioxidant effects in vivo. Studies in human subjects, reported that the consumption of $280 \mathrm{~g}$ of cherries (about 45 sweet Bing cherries) increased plasma lipophilic antioxidant capacity [23] [24]. Moreover, in a double-blind, placebo-controlled crossover design, tart cherry juice intake ( $240 \mathrm{~mL}$ twice daily for 14 days) was associated with a decrease of $\mathrm{F}(2)$-isoprostane levels, a marker of oxidative damage, in response to forearm ischemia-reperfusion. In the same subjects a decrease of urinary excretion of markers of oxidized nucleic acids (8-hydroxy-2'-deoxyguanosine, 8-hydroxyguanosine) was demonstrated [25].

\section{Conclusion}

In conclusion, our results show that maturity stage modulates phenol content, antioxidant and anti-glycation properties of "visciola" extracts. Information about factors which modulate phenol content and the health-promoting components of "visciola" may help farmers to better promote their healthy properties and could lead to an increased consumption of these fruits, including their use as functional food.

\section{Acknowledgements}

The authors wish to thank AlfioSantinelli for the help in managing the experimental field and Maurizio Antinori for his effort in collecting and drying the fruits.

\section{References}

[1] Kris-Etherton, P.M., Hecker, K.D., Bonanome, A., Coval, S.M., Binkoski, A.E. and Hilpert, K.F. (2002) Bioactive Compounds in Foods: Their Role in the Prevention of Cardiovascular Disease and Cancer. The American Journal of Medicine, 113, 71S-88S. http://dx.doi.org/10.1016/S0002-9343(01)00995-0

[2] Tangney, C.C. and Rasmussen, H.E. (2013) Polyphenols, Inflammation, and Cardiovascular Disease. Current Atherosclerosis Reports, 15, 324. http://dx.doi.org/10.1007/s11883-013-0324-x

[3] Babu, P.V.A., Liu, D.M. and Gilbert, E.R. (2013) Recent Advances in Understanding the Anti-Diabetic Actions of Dietary Flavonoids. Journal of Nutritional Biochemistry, 24, 1777-1789.

http://dx.doi.org/10.1016/j.jnutbio.2013.06.003

[4] Williamson, G. (2013) Possible Effects of Dietary Polyphenols on Sugar Absorption and Digestion. Molecular Nutrition \& Food Research, 57, 48-57. http://dx.doi.org/10.1002/mnfr.201200511

[5] Jariyapamornkoon, N., Yibchok-anun, S. and Adisakwattana, S. (2013) Inhibition of Advanced Glycation End Products by Red Grape Skin Extract and Its Antioxidant Activity. BMC Complementary and Alternative Medicine, 13, 171. http://dx.doi.org/10.1186/1472-6882-13-171

[6] Lavelli, V. (2009) Combined Effect of Storage Temperature and Water Activity on the Antiglycoxidative Properties and Color of Dehydrated Apples. Journal of Agricultural and Food Chemistry, 57, 11491-11497. http://dx.doi.org/10.1021/jf901865r

[7] Matsuda, H., Wang, T., Managi, H. and Yoshikawa, M. (2003) Structural Requirements of Flavonoids for Inhibition of Protein Glycation and Radical Scavenging Activities. Bioorganic \& Medicinal Chemistry, 11, 5317-5323. http://dx.doi.org/10.1016/j.bmc.2003.09.045

[8] Peng, X., Ma, J., Chen, F. and Wang, M. (2011) Naturally Occurring Inhibitors against the Formation of Advanced Glycation End-Products. Food \& Function, 2, 289-301. http://dx.doi.org/10.1039/c1fo10034c

[9] Shao, X., Bai, N.S., He, K., Ho, C.T., Yang, C.S. and Sang, S.M. (2008) Apple Polyphenols, Phloretin and Phloridzin: New Trapping Agents of Reactive Dicarbonyl Species. Chemical Research in Toxicology, 21, 2042-2050. http://dx.doi.org/10.1021/tx800227v

[10] Wu, C.H., Huang, S.M., Lin, J.A. and Yen, G.C. (2011) Inhibition of Advanced Glycation Endproduct Formation by Foodstuffs. Food \& Function, 2, 224-234. http://dx.doi.org/10.1039/c1fo10026b 
[11] Ahmed, N. (2005) Advanced Glycation Endproducts-Role in Pathology of Diabetic Complications. Diabetes Research and Clinical Practice, 67, 3-21. http://dx.doi.org/10.1016/j.diabres.2004.09.004

[12] Srikanth, V., Maczurek, A., Phan, T., Steele, M., Westcott, B., Juskiw, D. and Münch, G. (2011) Advanced Glycation Endproducts and Their Receptor RAGE in Alzheimer's Disease. Neurobiology of Aging, 32, 763-777. http://dx.doi.org/10.1016/j.neurobiolaging.2009.04.016

[13] Thornalley, P.J. (1996) Pharmacology of Methylglyoxal: Formation, Modification of Proteins and Nucleic Acids, and Enzymatic Detoxification-A Role in Pathogenesis and Antiproliferative Chemotherapy. General Pharmacology, 27, 565-573. http://dx.doi.org/10.1016/0306-3623(95)02054-3

[14] Wolff, S.P. and Dean, R.T. (1987) Glucose Autoxidation and Protein Modification. The Potential Role of “Autoxidative Glycosylation” in Diabetes. Biochemical Journal, 245, 243-250.

[15] Ames, B.N., Shigenaga, M.K. and Hagen, T.M. (1993) Oxidants, Antioxidants, and the Degenerative Diseases of Aging. Proceedings of the National Academy of Sciences of the United States of America, 90, 7915-7922. http://dx.doi.org/10.1073/pnas.90.17.7915

[16] Meydani, M. (2002) The Boyd Orr Lecture: Nutrition Interventions in Aging and Age-Associated Disease. Proceedings of the Nutrition Society, 61, 165-171. http://dx.doi.org/10.1079/PNS2002144

[17] Chaovanalikit, A. and Wrolstad, R.E. (2004) Total Anthocyanins and Total Phenolics of Fresh and Processed Cherries and Their Antioxidant Properties. Journal of Food Science, 69, FCT67-FCT72. http://dx.doi.org/10.1111/j.1365-2621.2004.tb17858.x

[18] Ferretti, G., Bacchetti, T., Belleggia, A. and Neri, D. (2010) Cherry Antioxidants: From Farm to Table. Molecules, 15, 6993-7005. http://dx.doi.org/10.3390/molecules15106993

[19] Goncalves, B., Landbo, A.K., Knudsen, D., Silva, A.P., Moutinho-Pereira, J., Rosa, E. and Meyer, A.S. (2004) Effect of Ripeness and Postharvest Storage on the Phenolic Profiles of Cherries (Prunus avium L.). Journal of Agricultural and Food Chemistry, 52, 523-530. http://dx.doi.org/10.1021/jf030595s

[20] Kirakosyan, A., Seymour, E.M., Llanes, D.E.U., Kaufman, P.B. and Bolling, S.F. (2009) Chemical Profile and Antioxidant Capacities of Tart Cherry Products. Food Chemistry, 115, 20-25. http://dx.doi.org/10.1016/j.foodchem.2008.11.042

[21] Heinonen, I.M., Meyer, A.S. and Frankel, E.N. (1998) Antioxidant Activity of Berry Phenolics on Human Low-Density Lipoprotein and Liposome Oxidation. Journal of Agricultural and Food Chemistry, 46, 4107-4112. http://dx.doi.org/10.1021/jf980181c

[22] Ou, B.X., Bosak, K.N., Brickner, P.R., Iezzoni, D.G. and Seymour, E.M. (2012) Processed Tart Cherry ProductsComparative Phytochemical Content, in Vitro Antioxidant Capacity and in Vitro Anti-Inflammatory Activity. Journal of Food Science, 77, H105-H112. http://dx.doi.org/10.1111/j.1750-3841.2012.02681.x

[23] Jacob, R.A., Spinozzi, G.M., Simon, V.A., Kelley, D.S., Prior, R.L., Hess-Pierce, B. and Kader, A.A. (2003) Consumption of Cherries Lowers Plasma Urate in Healthy Women. Journal of Nutrition, 133, 1826-1829.

[24] Prior, R.L., Go, L.W., Wu, X.L., Jacob, R.A., Sotoudeh, G., Kader, A.A. and Cook, R.A. (2007) Plasma Antioxidant Capacity Changes Following a Meal as a Measure of the Ability of a Food to Alter in Vivo Antioxidant Status. Journal of the American College of Nutrition, 26, 170-181. http://dx.doi.org/10.1080/07315724.2007.10719599

[25] Traustadottir, T., Davies, S.S., Stock, A.A., Su, Y., Heward, C.B., Roberts II, L.J. and Harman, S.M. (2009) Tart Cherry Juice Decreases Oxidative Stress in Healthy Older Men and Women. Journal of Nutrition, 139, 1896-1900. http://dx.doi.org/10.3945/jn.109.111716

[26] Diaz-Mula, H.M., Castillo, S., Martinez-Romero, D., Valero, D., Zapata, P.J., Guillen, F. and Serrano, M. (2009) Sensory, Nutritive and Functional Properties of Sweet Cherry as Affected by Cultivar and Ripening Stage. Food Science and Technology International, 15, 535-543. http://dx.doi.org/10.1177/1082013209351868

[27] Goldman, I.L., Kader, A.A. and Heintz, C. (1999) Influence of Production, Handling, and Storage on Phytonutrient Content of Foods. Nutrition Reviews, 57, S46-S52. http://dx.doi.org/10.1111/j.1753-4887.1999.tb01807.x

[28] Singleton, V.L., Orthofer, R. and Lamuela-Raventos, R.M. (1999) Analysis of Total Phenols and Other Oxidation Substrates and Antioxidants by Means of Folin-Ciocalteu Reagent. Methods in Enzymology, 299, 152-178. http://dx.doi.org/10.1016/S0076-6879(99)99017-1

[29] Gillespie, K.M., Chae, J.M. and Ainsworth, E.A. (2007) Rapid Measurement of Total Antioxidant Capacity in Plants. Nature Protocols, 2, 867-870. http://dx.doi.org/10.1038/nprot.2007.100

[30] Cheng, Z., Moore, J. and Yu, L. (2006) High-Throughput Relative DPPH Radical Scavenging Capacity Assay. Journal of Agricultural and Food Chemistry, 54, 7429-7436. http://dx.doi.org/10.1021/jf0611668

[31] Chung, B.H., Segrest, J.P., Ray, M.J., Brunzell, J.D., Hokanson, J.E., Krauss, R.M., Beaudrie, K. and Cone, J.T. (1986) Single Vertical Spin Density Gradient Ultracentrifugation. Methods in Enzymology, 128, 181-209. http://dx.doi.org/10.1016/0076-6879(86)28068-4 
[32] Bradford, M.M. (1976) A Rapid and Sensitive Method for the Quantitation of Microgram Quantities of Protein Utilizing the Principle of Protein-Dye Binding. Analytical Biochemistry, 72, 248-254. http://dx.doi.org/10.1016/0003-2697(76)90527-3

[33] Esterbauer, H., Striegl, G., Puhl, H. and Rotheneder, M. (1989) Continuous Monitoring of in Vitro Oxidation of Human Low Density Lipoprotein. Free Radical Research, 6, 67-75. http://dx.doi.org/10.3109/10715768909073429

[34] Gugliucci, A., Bastos, D.H., Schulze, J. and Souza, M.F. (2009) Caffeic and Chlorogenic Acids in Ilex paraguariensis Extracts Are the Main Inhibitors of AGE Generation by Methylglyoxal in Model Proteins. Fitoterapia, 80, 339-344. http://dx.doi.org/10.1016/j.fitote.2009.04.007

[35] Lunceford, N. and Gugliucci, A. (2005) Ilex paraguariensis Extracts Inhibit AGE Formation More Efficiently than Green Tea. Fitoterapia, 76, 419-427. http://dx.doi.org/10.1016/j.fitote.2005.03.021

[36] Goncalves, B., Landbo, A.K., Let, M., Silva, A.P., Rosa, E. and Meyer, A.S. (2004) Storage Affects the Phenolic Profiles and Antioxidant Activities of Cherries (Prunus avium L.) on Human Low-Density Lipoproteins. Journal of the Science of Food and Agriculture, 84, 1013-1020. http://dx.doi.org/10.1002/jsfa.1752

[37] Serrano, M., Guillen, F., Martinez-Romero, D., Castillo, S. and Valero, D. (2005) Chemical Constituents and Antioxidant Activity of Sweet Cherry at Different Ripening Stages. Journal of Agricultural and Food Chemistry, 53, 27412745. http://dx.doi.org/10.1021/jf0479160

[38] Serrano, M., Diaz-Mula, H.M., Zapata, P.J., Castillo, S., Guillen, F., Martinez-Romero, D., Valverde, J.M. and Valero, D. (2009) Maturity Stage at Harvest Determines the Fruit Quality and Antioxidant Potential after Storage of Sweet Cherry Cultivars. Journal of Agricultural and Food Chemistry, 57, 3240-3246. http://dx.doi.org/10.1021/jf803949k

[39] Blando, F., Gerardi, C. and Nicoletti, I. (2004) Sour Cherry (Prunus cerasus L.) Anthocyanins as Ingredients for Functional Foods. Journal of Biomedicine and Biotechnology, 2004, 253-258. http://dx.doi.org/10.1155/S1110724304404136

[40] Bonnefont-Rousselot, D. (2002) Glucose and Reactive Oxygen Species. Current Opinion in Clinical Nutrition \& Metabolic Care, 5, 561-568. http://dx.doi.org/10.1097/00075197-200209000-00016

[41] Bacchetti, T., Masciangelo, S., Armeni, T., Bicchiega, V. and Ferretti, G. (2014) Glycation of Human High Density Lipoprotein by Methylglyoxal: Effect on HDL-Paraoxonase Activity. Metabolism-Clinical and Experimental, 63, 307-311. http://dx.doi.org/10.1016/j.metabol.2013.10.013

[42] Nagaraj, R.H., Oya-Ito, T., Padayatti, P.S., Kumar, R., Mehta, S., West, K., et al. (2003) Enhancement of Chaperone Function of Alpha-Crystallin by Methylglyoxal Modification. Biochemistry, 42, 10746-10755. http://dx.doi.org/10.1021/bi034541n

[43] Shao, X., Chen, H., Zhu, Y., Sedighi, R., Ho, C.T. and Sang, S. (2014) Essential Structural Requirements and Additive Effects for Flavonoids to Scavenge Methylglyoxal. Journal of Agricultural and Food Chemistry, 62, 3202-3210. http://dx.doi.org/10.1021/jf500204s

[44] Peng, X., Ma, J., Chao, J., Sun, Z., Chang, R.C., Tse, I., Li, E.T.S., Chen, F. and Wang, M.F. (2010) Beneficial Effects of Cinnamon Proanthocyanidins on the Formation of Specific Advanced Glycation Endproducts and MethylglyoxalInduced Impairment on Glucose Consumption. Journal of Agricultural and Food Chemistry, 58, 6692-6696. http://dx.doi.org/10.1021/jf100538t

[45] Fazzari, M., Fukumoto, L., Mazza, G., Livrea, M.A., Tesoriere, L. and Di Marco, L. (2008) In Vitro Bioavailability of Phenolic Compounds from Five Cultivars of Frozen Sweet Cherries (Prunus avium L.). Journal of Agricultural and Food Chemistry, 56, 3561-3568. http://dx.doi.org/10.1021/jf073506a

[46] Manach, C., Scalbert, A., Morand, C., Remesy, C. and Jimenez, L. (2004) Polyphenols: Food Sources and Bioavailability. American Journal of Clinical Nutrition, 79, 727-747.

\section{Abbreviations}

Advanced glycation end products, AGEs; serum bovine albumin, BSA; low density lipoproteiens, LDL; methylglyoxal, MGO; oxygen radical absorbance capacity, ORAC; 2,2-diphenyl-1-picrylhydrazyl radical, DPPH; reactive oxygen species, ROS; reactive carbonyl species, RCS. 
Scientific Research Publishing (SCIRP) is one of the largest Open Access journal publishers. It is currently publishing more than 200 open access, online, peer-reviewed journals covering a wide range of academic disciplines. SCIRP serves the worldwide academic communities and contributes to the progress and application of science with its publication.

Other selected journals from SCIRP are listed as below. Submit your manuscript to us via either submit@scirp.org or Online Submission Portal.
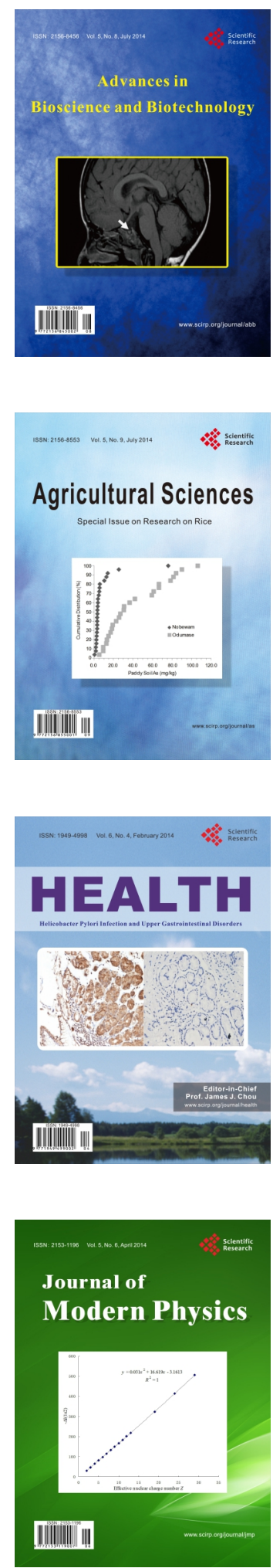
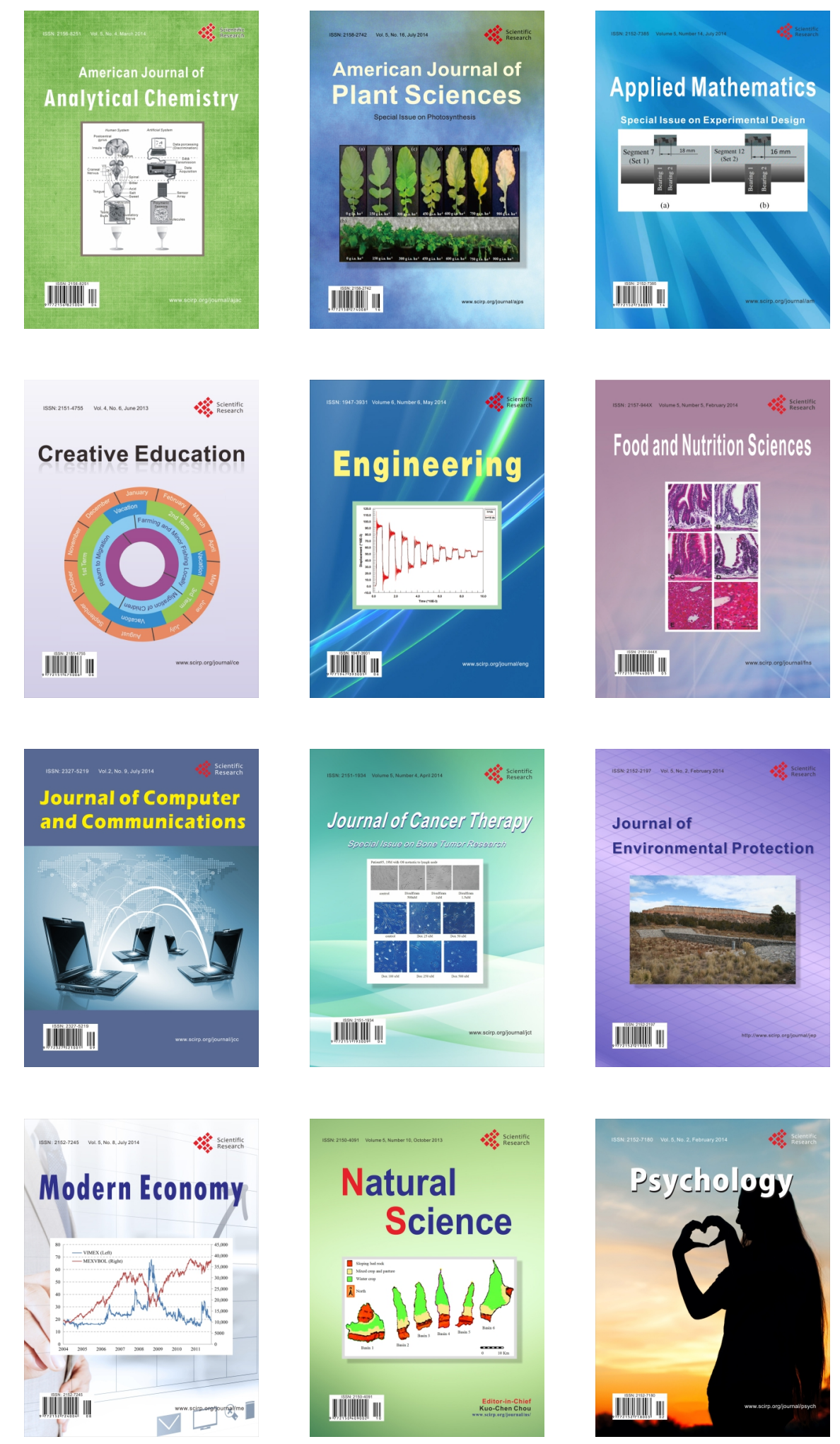